\title{
"Monstro esperançoso": a respeito de Oratório, de André Vallias
} Rejane C. Rocha ${ }^{1}$

O que a cultura ocidental designa sob o termo literatura é, de acordo com o medievalista Paul Zumthor (1989), um fato cultural complexo, mas transitório. A afirmação do estudioso remete ao fato de que a literatura, tal qual a compreendemos neste estudo - não restrita à textualidade, mas também composta pelas condições de produção material e circulação dos textos -, constrói-se graças a uma conjuntura histórica que engendra, entre outras coisas, uma condição técnica específica: a invenção e a consolidação da imprensa, que permitiu a passagem da cultura manuscrita à cultura tipográfica, em um longo processo ocorrido no século XIX.

Partindo desse pressuposto, há que se considerar a hipótese de haver outra condição histórica que engendre uma nova condição técnica para construir um objeto literário diferente ou outra compreensão do termo "literatura". Diante das condições de produção material e de circulação das textualidades na contemporaneidade digital, que pressupõem outros modos de inscrição, leitura e valoração do literário, esta reflexão pretende problematizar os limites do conceito de literatura, questionando em que medida seus contornos, tal qual se consolidaram ao longo do tempo, podem abrigar as textualidades digitais.

Para proceder a essa discussão, devemos, ainda que brevemente, refletir sobre o processo de surgimento e consolidação do termo literatura. Isso permitirá considerar o quanto tal termo, tão naturalizado pela teoria literária, sobretudo a partir do início do século $\mathrm{XX}$, acolhe sob sua formulação semântica complexos processos de julgamento e de valoração que pressupõem também amplas negociações comunitárias, que não estão isentas das conjunturas históricas, culturais e técnicas.

Ao enfrentar esse percurso, menos do que elaborar uma remissão histórica exaustiva, o que se pretende é afastar qualquer designação essencialista do que seja o objeto literário. Só assim, atentos à complexidade do termo e às ambivalências que, ao longo dos séculos, o caracterizam, é possível ampliar suas fronteiras, a fim de que ele possa

\footnotetext{
${ }^{1}$ Doutora em Estudos Literários e professora da Universidade Federal de São Carlos (UFSCar), São Carlos, SP, Brasil. E-mail: rjncris@ gmail.com
} 
acolher as manifestações literárias que surgem no contexto digital. Se estivermos atentos ao fato de que a literatura não é, somente, o texto e que ela não surgiu per se e nem se mantém per se, podemos começar a questionar quais são as especificidades do contexto digital. E entendê-lo não como um espaço pelo qual podemos ou não optar na contemporaneidade, mas como um modo de vida inevitável a todo ser humano, na atualidade. Ou seja, modos de sentir, perceber, criar - que possibilitariam a emergência de uma expressão literária que, a um só tempo (como qualquer objeto artístico sói fazer) é expressão, tradução, compreensão e criação do universo simbólico relacionado a esse contexto.

Delineia-se, assim, para esta reflexão, uma organização tripartite, na qual se questionam: i) os limites históricos e as limitações teóricas do termo literatura; ii) a tentativa de delineamento do que estamos designando como contexto digital; e iii) a discussão a respeito de um objeto artístico que, pertencendo a esse contexto, força a revisão daqueles limites e limitações.

Embora se possa questionar a validade e a produtividade de se examinar e talvez acatar a ampliação semântica do termo literatura, acreditamos ser inescapável a reflexão crítica a respeito da forma como as poéticas digitais possibilitam, impelem e refletem a indefinição dos limites entre os diversos tipos de expressões artísticas e tipologias discursivas, levando-nos ao encontro de uma época em que tais distinções não faziam sentido.

\section{Literatura}

Ao localizar, nos séculos XII a XV, uma espécie de pré-história da literatura, Paul Zumthor (1989) chama a atenção para dois fatos: i) na história das culturas, nem sempre o que hoje está recoberto pelo termo "literatura" existiu; e o próprio termo nem sempre significou o que passou a designar a partir da Modernidade. ${ }^{2} \mathrm{O}$ medievalista constrói

\footnotetext{
${ }^{2}$ No verbete "Literatura" do E-dicionário de termos literários, coordenado por Carlos Ceia, Roberto Acízelo de Souza (2010) esclarece que é controversa a discussão a respeito da origem e significados do termo. Tanto que, segundo o autor, pode-se observar, nas discussões a respeito, a formação de dois grupos: de um lado, aqueles que defendem a hipótese de que os fatos literários existiram antes mesmo da emergência do vocábulo "literatura"; de outro, os que sublinham o fato de que só se pode falar de literatura no momento em que o termo assuma sua concepção moderna - o autor menciona uma reciclagem do termo por volta do século XVIII. Paul Zumthor, por sua vez, admite que se pode encontrar traços dispersos do que viria a se caracterizar como literatura, no século XVIII, já nas
} 
sua argumentação pela recensão a uma realidade histórica que localiza no século XII o que seria uma primeira cristalização de elementos, os quais, muito mais tarde, fariam parte da concepção de literatura que ainda hoje prevalece: a ideia de autor e as práticas impostas por tal ideia; e o início do surgimento de uma "zona de cultura", ou seja, o surgimento de práticas que se apartam da vida cotidiana e assumem feições não pragmáticas.

Durante os séculos XIV e XV, a ideia de autoria aprofunda-se, gerando tentativas de, por meio da organização de antologias, resguardar os textos do esquecimento, provocando, ainda, um efeito secundário, que é o da personalização crescente do discurso poético - o que retroalimentava a autoria. O distanciamento entre o "eu" que escrevia e o seu texto e o seu público - algo que paulatinamente começa a acontecer e caracterizaria a substituição da cultura oral pela cultura manuscrita e, depois, impressa - aprofunda-se no momento em que a difusão da imprensa torna possível, ao mesmo tempo que exige, a autonomia do discurso poético:

Este fato [a difusão da imprensa] marcou a poesia assim difundida, menos em sua forma aparente que em suas intenções motrizes, com abertura a um público mais impessoal, ao mesmo tempo que se produzia um distanciamento do eu que escrevia [...]. O discurso poético se dobra, encerra-se em seu próprio prazer e busca em si mesmo sua justificação, com uma liberdade: essa interiorização, decorrente das circunstancias de uma sociedade transformada, foi, sem dúvida, o fator constitutivo de nossas "literaturas" (Zumthor, 1989, p. 345-346, tradução nossa).

É no século XVIII que a moderna concepção de literatura se consolida, graças ao que Paul Zumthor (1989) identifica como a sua "institucionalização", compreendida como a construção de um campo, exigida pelo aprofundamento da divisão social do trabalho, quando "observa-se o crescimento da distância conceitual entre razão e imaginação, atribuindo-se competências específicas para a configuração verbal de cada uma dessas experiências". ${ }^{3}$

novelas que, no século XII, eram objetos concebidos na forma escrita para serem declamados - o que as distancia de um produto típico da cultura oral.

${ }^{3}$ Ver verbete "Literatura", de Roberto Acízelo de Souza, no E-dicionário de termos literários (2010). 
Deve-se entender a consolidação da concepção de literatura em paralelo ao surgimento das suas disciplinas "parasitas" (história e crítica, por exemplo), à normatização e à regulação da linguagem e ao estabelecimento do valor literário. Além disso, é esse mesmo século que presencia o modo como o termo literatura serve à nomeação de "um conjunto de representações e de tendências errantes" (Zumthor, 1989, p. 341, tradução nossa) associadas tardiamente entre si.

Digno de nota é também o fato de que ao termo literatura acoplaram-se noções que vieram a se tornar parâmetros críticos e efetivamente fundaram, consolidaram e sustentam nossa compreensão do termo. Seguimos, ainda, Paul Zumthor (1989, p. 341, tradução nossa) na enumeração dessas noções/parâmetros:

ideia de um sujeito enunciador autônomo, da possibilidade de captação do outro, da concepção de um objeto reificado, da preponderância concedida à referencialidade da linguagem e, de forma simultânea, à ficção, pressuposição de certa supratemporalidade de certo tipo de discurso socialmente transcendente, suspenso em um espaço vazio e que constitui por si só uma Ordem.

Se a recensão aqui brevemente esboçada não faz jus à complexidade do processo histórico de, pelo menos, seis séculos, ela é útil para que se compreenda que o percurso de construção dos significados atribuídos ao termo evidencia que é forçoso o afastamento de qualquer concepção de literatura pautada na crença na existência de um conjunto de textos que, de acordo unicamente com as suas características imanentes, seriam dignos de assumir tal designação. Isso porque, entre outros motivos, as noções gerais/parâmetros que constituem o que compreendemos por literatura não são simplesmente a tradução de valores estéticos ou estruturais; antes, são resultado de uma complexa conjuntura sócio-histórica, técnica e cultural que engendra critérios de julgamento e valoração, já que o termo também funciona como um rótulo de distinção atribuído a determinado conjunto de textos por meio de negociações - quase nunca explícitas que pressupõem práticas normativas comuns à determinada sociedade/comunidade (Lentricchia e Mclaughlin, 1995, p. 183).

Por seu turno, é tributário das noções/parâmetros que fundamentaram a concepção moderna de literatura e dos processos de avaliação e valoração que concorreram para a institucionalização do fenômeno o conceito de obra 
literária. A despeito da variedade de abordagens teóricas, pode-se compreender o conceito como propõe Reinaldo Laddaga (2002, p. 18), em formulação muito pertinente e concernente às reflexões que aqui temos acompanhado, de Paul Zumthor (1994):

Uma sequência fixa de linguagem que se subtrai à mera circulação de mensagens, que se encontra individualizada de tal modo que, se algo for modificado nela, modifica por completo a sua natureza. Uma obra se destaca, se separa, se distancia do lugar onde surge, para oferecer uma experiência de singular intensidade. Experiência que deveria exceder o espaço das práticas cotidianas (Laddaga, 2002, p. 18).

A questão que se deve enfrentar diz respeito ao fato de, como tentamos demonstrar, tais noções de literatura e de obra literária estarem intimamente relacionadas com condições de contorno muito específicas: a passagem da cultura oral e manuscrita para a cultura impressa, e a consolidação desta última com a popularização da imprensa; a emergência da ideia de sujeito; a crescente autonomia dos campos do saber; e a divisão social do trabalho.

Se não é verdade que todas as condições conjunturais sofreram drásticas alterações desde o século XVIII até os nossos dias, também não se pode afirmar que elas se mantêm idênticas. Basta observarmos, para os limites deste artigo, a emergência dos meios digitais, cuja popularização alterou profundamente não só a maneira como nos comunicamos, mas também a forma como percebemos o mundo, o modo como representamos tal percepção, nossas práticas culturais. Em suma, há que se admitir, com Kucinskas e Moser (2007, p. 28), em uma remissão a McLuhann, que "as novas tecnologias modificam nossa experiência do mundo, porque elas mudam, na realidade, as próprias condições da experiência estética". E a literatura?

Os atuais modos de produção, de inscrição, de veiculação e de leitura dos textos, no contexto digital desafiam as categorias forjadas (jurídicas, estéticas, biblioteconômicas e administrativas) quando do estabelecimento da cultura impressa (Chartier, 2012, p. 86). E se, como vimos apontando, o conceito de literatura e de obra literária relaciona-se com tais categorias, não é ocioso questionar se estaremos diante também de uma reformulação de ambos. 


\section{Contexto digital}

É complexo definir o que se compreende por contexto digital, haja vista o fato de que sua definição depende do ponto de vista da abordagem: trata-se de uma abordagem técnica, cultural, filosófica, social? $O$ que se pretende é analisar as implicações éticas, estéticas, políticas? Evidentemente, o termo só se estabeleceria de forma minimamente clara se pudéssemos fazer uma discussão que contemplasse todas essas abordagens, articulando dados e cotejando elementos, o que seria inviável, dados os limites desta proposta de reflexão. Portanto, propõe-se acompanhar a discussão de Geofrey Nunberg (1993), que não se detém na especificidade do literário, mas nos ajuda a compor um panorama contextual do que ele nomeia como "age of electronic reproduction" e que poderíamos traduzir para o português, a partir das ressonâncias da tradução do título do célebre ensaio de W. Benjamim - "A obra de arte da era de sua reprodutibilidade técnica" -, como a "era da reprodutibilidade eletrônica". Refletir sobre a especificidade das formas de criação, reprodução e fruição textual no momento da emergência dos meios de comunicação digital poderia ajudar a delinear alguns aspectos do que seja o contexto digital no âmbito da produção, da circulação e da leitura do texto literário.

Refletindo sobre "o futuro dos livros", Nunberg (1993) defende que a introdução de uma nova tecnologia transforma as formas culturais existentes. As ressalvas necessárias relativas a essa afirmação dizem respeito ao fato de que ela pressupõe uma dicotomia "tecnologia" versus "cultura". A técnica, no entanto, faz parte do universo cultural da humanidade e a cultura não prescinde da técnica para sua execução. Tentar escapar ao determinismo tecnológico que ronda a afirmação do autor, no entanto, não deve impedir-nos de observar que, por exemplo, parte dos livros impressos que não fazem parte do universo cultural, documentos de uso imediato e dirigido - manuais, por exemplo - já está dando lugar às formas eletrônicas. Se o impresso está desaparecendo em vários setores, a questão pertinente que emerge daí é: "Pode haver cultura de impressão após a impressão?" (Numberg, 1993, p. 15). Ou seja, em uma sociedade em que cada vez mais acessamos os textos em versões digitalizadas - e não é raro encontrar pessoas que preferem ler textos, mesmos os disponíveis em versão impressa, no formato digital -, haverá sobrevida para uma textualidade impressa? 
Note-se que a questão levanta problemas mais complexos que os da simples "substituição" de um suporte por outro, uma vez que, há que se lembrar, mesmo os textos que se veiculam primariamente por meio impresso podem ser lidos no formato digital e, provavelmente, foram concebidos nesse mesmo formato. Assim, deve-se se admitir que, na era da reprodutibilidade eletrônica, estamos diante de uma alteração no letramento engendrado pelo impresso, uma vez que

quaisquer meios de comunicação ou mídias são inseparáveis das formas de socialização e cultura que são capazes de criar, de modo que o advento de cada novo meio de comunicação traz consigo um ciclo cultural que lhe é próprio (Santaella, 2003, p. 64).

Trata-se, assim, de uma complexa rede de relações entre os suportes e meios nos quais os textos em geral são veiculados e as práticas de escrita e leitura que se desenvolvem nesses diferentes meios. É necessário sublinhar que essa complexa rede de relações importa para a discussão na medida em que os meios de comunicação - e nesse aspecto Numberg (1993) retoma muitas das reflexões de Chartier - não são transparentes, ou seja, não se constituem como meros veículos que entregam determinado conteúdo à mente do leitor, de maneira direta e inequívoca; antes, são dispositivos que exigem um engajamento do corpo, que compõem a rede de significados do texto, que não "desaparecem" no ato de leitura. Disso se conclui que a leitura - em suas mais diversas atualizações - não é um ato puramente intelectual, abstrato, já que ele exige uma inscrição do corpo no espaço, que se alterará de acordo com os dispositivos em que os textos se inscrevem.

Nesse sentido, e ao se refletir sobre as alterações nas práticas de leitura ao longo da história, fica evidente que ler na tela (hoje diríamos, nas telas) é diferente de ler na página impressa. E poderíamos nos questionar se essa diferença é maior ou menor na medida em que as telas se propõem a "reproduzir" algumas das propriedades do papel ou, ainda, como indaga Numberg (1993, p. 18), se um livro eletrônico genuíno seria aquele dispositivo que conseguisse reproduzir as propriedades do livro tradicional, ao mesmo tempo que trouxesse as características típicas de um texto eletrônico: pudesse ser apagado, alterado, anotado, pesquisado etc. E, ainda, se essa diferença - entre ler na tela e ler na página impressa importa na apreensão/construção dos significados do que se lê.

A questão que se coloca, então, é: se os artefatos em que se inscrevem e em que se leem os textos mudam, as formas discursivas tradicionais 
seriam substituídas por novas formas discursivas, talvez mais adequadas à leitura nesses novos dispositivos? Ainda que o questionamento não esteja de acordo com as reflexões desenvolvidas por muitos teóricos ${ }^{4}$ que evidenciam uma convivência entre diferentes meios de comunicação e práticas por eles engendradas, não é ocioso questionar se, em um contexto em que as textualidades são outras - e seus processos de escrita, leitura, reprodução e valoração também - as concepções de literatura e de obra literária, como as discutimos na primeira seção deste trabalho, manter-se-ão as mesmas. ${ }^{5}$

Considerando o que foi esboçado até aqui, percebe-se que esses questionamentos só são pertinentes quando se ousa olhar para essas textualidades engendradas pelo contexto digital a partir de uma reflexão acerca do literário. $\mathrm{O}$ gesto é ousado, porque: i) a produção de objetos literários pensados especificamente para o meio digital é, sobretudo no Brasil, ainda incipiente em termos de quantidade - constatação que poderia ser complementada e, quem sabe, problematizada ao se considerar questões atinentes à acessibilidade das obras, haja vista problemas relativos à compatibilidade dos programas usados na sua concepção e leitura e à instabilidade do ambiente digital conectado em rede; ii) tais objetos parecem, ainda, ser o resultado de uma espécie de "teste de canal", no sentido de que os artistas estão tateando as possibilidades técnicas e as melhores maneiras de mobilizá-las em favor da expressão de um conteúdo com interesse estético; iii) a plasticidade do meio - as inúmeras possibilidades de fazer convergir, ${ }^{6}$ em um único objeto, diferentes mídias (sonoras, imagéticas, textuais) - possibilita a elaboração de objetos limítrofes entre as esferas de diferentes expressões artísticas; e iv) os artistas que se dedicam à elaboração de tais objetos raramente se autodenominam escritores e raramente denominam suas obras como "literatura".

Obviamente, uma opção à ousadia seria a de partir do pressuposto de que esses objetos não pertencem ao campo de interesse dos estudos

\footnotetext{
${ }^{4}$ Entre eles Bolter e Grusin (2000) e Santaella (2003).

${ }^{5}$ Uma breve e despretensiosa incursão pelas obras mais interessantes - este também é um critério de valoração que se deve explicitar: as obras mais interessantes são aquelas que usam de maneira produtiva as potencialidades do meio digital para construir objetos literários que não sobreviveriam em outro meio de inscrição, que não o digital - demonstra que seus autores não se denominam escritores nem caracterizam suas criações como literatura.

${ }^{6}$ Costa (2002, p. 81) explica o fenômeno da convergência da seguinte forma: "Cada texto ou mensagem - textual, sonora ou imagética - se transforma em espaço de memória, em fluxo informacional, em bits".
} 
literários, uma vez que, de forma mais fácil e inequívoca, poder-se-ia designá-los como performances, webart, artes visuais... No entanto, isso não seria a proposição ou o acatamento de uma restrição de campo? Se, como vimos, as textualidades (e os modos de inscrição, circulação e leitura) no contexto digital têm sofrido alterações e se os conceitos de literatura e obra literária não são tão estáveis quanto gostaríamos de crer, talvez seja imprescindível que abordemos esses objetos desde o campo da literatura. Assim, enfrentaremos dois movimentos: o da análise desses objetos a partir de parâmetros críticos dos estudos literários e o do questionamento e, quem sabe, ampliação desses parâmetros com base na análise desses objetos.

\section{Percursos e percalços}

Se as dificuldades que, descritas no parágrafo anterior, tornam o gesto de ler objetos digitais a partir do campo literário um gesto ousado, há que se considerar se a dificuldade não se relaciona mais com as limitações impostas pelo próprio campo - cujas origens tentamos delinear brevemente na primeira seção deste artigo, chamando a atenção para o quanto elas se relacionam com critérios de valor que extrapolam a inerência dos objetos literários - do que com as características "não literárias" desses objetos digitais. Nossa intuição acompanha a de Pedro Reis (2012, p. 261), quando observa que:

As potencialidades dos media digitais aplicadas à criação literária levam-nos, pois, a identificar condições inéditas de produção que transformam e transtornam desde logo a noção de texto da literatura dominante enquanto realização verbal impressa, logo fixa e inalterada, assim como conferem renovadas possibilidades a caraterísticas já conceptualizadas em tendências experimentais anteriores, ao mesmo tempo em que permitem a criação de novas características textuais.

Na medida em que a ousadia nos liberta para propor percursos, ao invés de lamentar os percalços, há que se ler esses objetos digitais à luz do que viria a ser a literatura no contexto digital. ${ }^{7}$ Sublinhe-se que essa

\footnotetext{
${ }^{7}$ A esse respeito, afirma Katherine Hayles (2009, p. 21) que a literatura produzida no contexto digital (à qual ela nomeia como "literatura eletrônica") é um "'monstro esperançoso' (como os geneticistas chamam as mutações adaptativas) composto por partes extraídas de diversas tradições [impressa, digital etc.] e que nem sempre se posicionam juntas de forma organizada".
} 
proposição aposta no vir a ser, na medida em que a leitura dessas obras como literatura só tem lugar no interior de uma concepção de literatura que se (re)construiria pela leitura dessas obras. De qualquer maneira, não é esse o percurso de legitimação de qualquer expressão artística?

Um esclarecimento é necessário, contudo, antes de propor a leitura de uma obra. Ele parte da constatação de que o ambiente digital comporta os mais diferentes perfis de objetos textuais que o povoam: obras originalmente concebidas para serem inscritas em suportes impressos e que, digitalizadas, veem a ampliação da sua circulação para, em seguida, serem de novo publicadas em livro impresso; ${ }^{8}$ obras concebidas em formatos compatíveis para a leitura em dispositivos de leitura eletrônicos - sem mencionar aquelas concebidas para serem impressas e que, digitalizadas, passaram a ser lidas nas telas; blogs, sites e páginas nas redes sociais que abrigam os textos literários de autores estreantes - ou nem tão estreantes assim - que percebem na possibilidade de veiculação digital de seus textos uma manobra para evitar ou seduzir o mercado editorial; obras que mobilizam, em sua fatura, as especificidades do meio digital, colocando essas especificidades técnicas em contato dialógico com o conteúdo que se pretende transmitir. ${ }^{9}$ Por uma questão de opção metodológica, é esse último perfil de obra que abordaremos na leitura que se segue. São obras que acatam e evidenciam as possibilidades e, por que não dizer, as limitações do meio e as transformam em experiências significativas esteticamente. ${ }^{10}$

\footnotetext{
${ }^{8}$ Alckmar Luiz dos Santos (2003, p. 34) exemplifica com o caso de A carta de Caminha, que, ao entrar para o acervo do belo projeto de disponibilização de obras clássicas da literatura brasileira em formato digital, desenvolvido pelo Núcleo de Pesquisas em Informática, Literatura e Linguística (NUPILL) da Universidade Federal de Santa Catarina, e reinscrevendo-se no circuito de mediações e trocas culturais, passou a ser publicada em meio impresso a partir da versão digitalizada elaborada pelo núcleo.

${ }^{9}$ O site brasileiro Literatura Digital (www.literaturadigital.com.br) pretende ser um repositório desse tipo de obra; no entanto, por motivos que aqui não cabe discutir, ele está, ainda, muito aquém em número de obras e autores reunidos do que os dois volumes (2006 e 2011) da já muito referenciada e respeitada antologia organizada pela Electronic Literature Organization, que inclui autores brasileiros, e, mesmo, de outros sites que, sem ambicionarem o status de repositório, são bons meios de referência ao que se tem produzido, no Brasil, nesses termos.

${ }^{10}$ Grácio e Portela (2012) estabelecem ampla e produtiva discussão a respeito de critérios de caracterização de blogs e sites que abrigam obras de literatura digital. Segundo os autores, é possível estabelecer níveis de materialidade digital nas obras - no nível "A" teríamos a simples presença da remediação, ou seja, da passagem, substituição da materialidade impressa para a materialidade digital; no nível "C" teríamos obras cuja composição é determinada pelo software, o que exige que as obras sejam executadas pelos programas.
} 
Se tal opção metodológica oferece-nos um primeiro e importante critério de seleção - o que não significa que os outros perfis de obras enumerados anteriormente não contribuam para o estabelecimento e consolidação do literário no contexto digital -, ele antepõe outras dificuldades: essas especificidades técnicas do meio não raro estão relacionadas com a caracterização do meio digital como um metameio, como coloca Follain (2010), ou como um meio convergente, como prefere Jenkins (2009) e Santaella (2003), ou, ainda, como um meio multimodal, como defende Pierre Lévy (2008).

Embora em alguns pontos divergentes, essas qualificações do meio digital chamam a atenção para o fato de que é inerente a ele a possibilidade de manipular diferentes linguagens, que causarão diferentes resultados sensoriais no leitor. Gracio e Portela (2012, p. 322) destacam que:

Na medida em que a diferença entre práticas artísticas depende da diferença entre os meios que as definem enquanto práticas especializadas, a crescente convergência dos media decorrente da tecnologia digital tende a produzir formas e gêneros híbridos, difíceis de apreender dentro das instituições e das categorias de percepção anteriores.

Implicada nisso está a constatação - talvez a mais incômoda para os estudiosos de literatura - de que esses objetos literários arquitetados para o ambiente digital não se compõem exclusivamente pela mobilização da linguagem verbal. A esse respeito, Santos e Sales (2011, p. 18-19) sublinham que:

Na delimitação do campo literário, feita por críticos e teóricos, confundia-se predomínio com exclusividade da matéria verbal. Por conseguinte, quase sempre, as tentativas de propor conceitos e gêneros para as literaturas, passavam exclusivamente pelas estratégias associadas a essa matéria. Ora, nas últimas décadas, com as possibilidades abertas pelo digital, concretizou-se a utilização de diferentes elementos na criação literária.

Os autores ainda salientam que um dos critérios possíveis para o exame crítico dessas produções digitais é o equilíbrio entre matéria verbal e outras expressões produzidas pelo meio digital, tais como a visualidade das imagens, a sonoridade e a cinestesia. É ainda Alckmar Luiz dos Santos (2003) que elabora criticamente o que viria a ser esse 
"equilíbrio" entre a matéria verbal e outros elementos constituintes dos objetos literários digitais, chamando a atenção para a necessidade de uma conjunção - e não, simplesmente, justaposição - desses elementos:

A novidade talvez esteja sobretudo no modo como as enormes quantidades e a grande velocidade do meio eletrônico geram artifícios e processos de significação que correm paralelamente aos significantes tradicionais (verbais, icônicos, sonoros, imagéticos etc.) sem se confundir com eles e sem os esconder, mas permitindo o mapeamento de espaços heterogêneos e multidimensionais de produção de sentidos. É justamente nesses espaços que o verbal é lido também (e principalmente) através e dentro do eletrônico; em que o eletrônico se manifesta dentro dos limites e das operações possíveis da matéria verbal (Santos, 2003, p. 63, grifos nossos).

Levar em consideração os pressupostos de Grácio e Portella (2012) e de Santos e Sales (2011) é, a um só tempo, perceber que os limites do que designamos como "literatura" talvez sejam estreitos para acomodar as expressões híbridas que surgem nessa época de convergência de mídias no ambiente digital. Ao mesmo tempo, é compreender que o que quer que designemos como cultura literária na atualidade estará relacionado não só com as condições de contorno que engendram o contexto digital, e suas práticas de leitura e de escrita, mas também com a incontornável herança literária que a cultura impressa nos legou.

André Vallias inicia seu percurso pela seara da literatura digital em 1989, na Alemanha. Embora o início de suas investigações poética e visual tenha se dado antes disso, é quando conhece as reflexões de Vilém Flusser e compra seu primeiro computador que suas experiências poéticas que mobilizam as potencialidades de uma tecnologia então emergente têm início.

Vale a pena sublinhar que, desde o início de suas experiências artísticas, inclusive antes da sua incursão pelo AutoCAD (software com o qual desenvolveu seus primeiros poemas digitais), o autor tensionava os limites entre suportes e linguagens: a pesquisa em serigrafia e a convergência dessa linguagem visual com as experiências poéticas do Concretismo foi que possibilitou o seu début 
poético. Da década de 1990 aos dias de hoje, ${ }^{11}$ André Vallias produziu uma obra considerável para o corpus da literatura digital, e muitas das suas experiências poético-literárias fazem parte de antologias ou são referenciadas em obras críticas ou em repositórios da produção literária digital. ${ }^{12}$

Oratório $^{13}$ foi concebida no ano de 2003 e, atualmente, está disponível no site de André Vallias. Uma performance com o poema, realizada pelo próprio Vallias, está disponível em seu canal no Youtube. A tela inicial oferece ao leitor, além do título, o subtítulo da obra e algo que poderíamos identificar a uma epígrafe - exibida, alternadamente, em italiano e em sua tradução para o português -, de autoria Giambatista Vico.

Nessa página inicial, a condição estática do texto é rompida apenas por uma espécie de sobreposição das letras do título (pressentida pela captura de tela reproduzida na figura 1) e pela alternância da língua da epígrafe, entre o latim e o português, quando o leitor passa o cursor sobre esses espaços da tela. O silêncio impera, mas não dura.

\footnotetext{
${ }^{11}$ O mapeamento das datas das obras de André Vallias foi feito por Maíra Borges Wiese (2012), a partir de entrevista concedida pelo autor e anexada a sua dissertação de mestrado intitulada $A$ poesia digital de André Vallias. Desse mapeamento depreende-se que a última obra com esse perfil, produzida pelo autor, foi o "Poema civil n. 1", de 2006, e que ele tem, recentemente, atuado como designer gráfico e colaborado na produção de obras disponibilizadas no site da revista Errática, editada por ele e por Eucanaã Ferraz. Sublinhe-se que, no contexto digital de produção, circulação e leitura de literatura, é sobremaneira difícil estabelecer os limites relacionados à autoria, data de "publicação" (as obras, muitas vezes, possuem mais de uma versão, às vezes sensivelmente diferentes entre si, surgidas em datas diferentes) e o que se deve - ou não - agregar à "obra" do autor. Fica a questão, para ser respondida em momento oportuno: as intervenções que Vallias afirma fazer nos poemas publicados da revista Errática são apenas "intervenções" técnicas em poemas concluídos ou constituem efetivamente uma espécie de coautoria que exige que o leitor - e a crítica literária - estejam aptos para "ler através do eletrônico" e ver a manifestação do eletrônico "dentro dos limites da matéria verbal" (Santos, 2003, p. 60).

${ }^{12}$ É o caso, por exemplo, do site da Electronic Literature as a Model of Creativity and Innovation in Practice (ELMC).

13 Informações técnicas: "Software AutoCAD, Illustrator, Flash. Composição musical dos três "quadros" "Passarela do samba", "Corcovado", "Favela da Rocinha": colagem sonora feita por mim a partir de diversas composições musicais, alteradas no SoundEdit. Composição do elemento sonoro do "quadro" inicial e do "quadro" principal: idem." (Vallias apud Wiese, 2012, p. 110).
} 


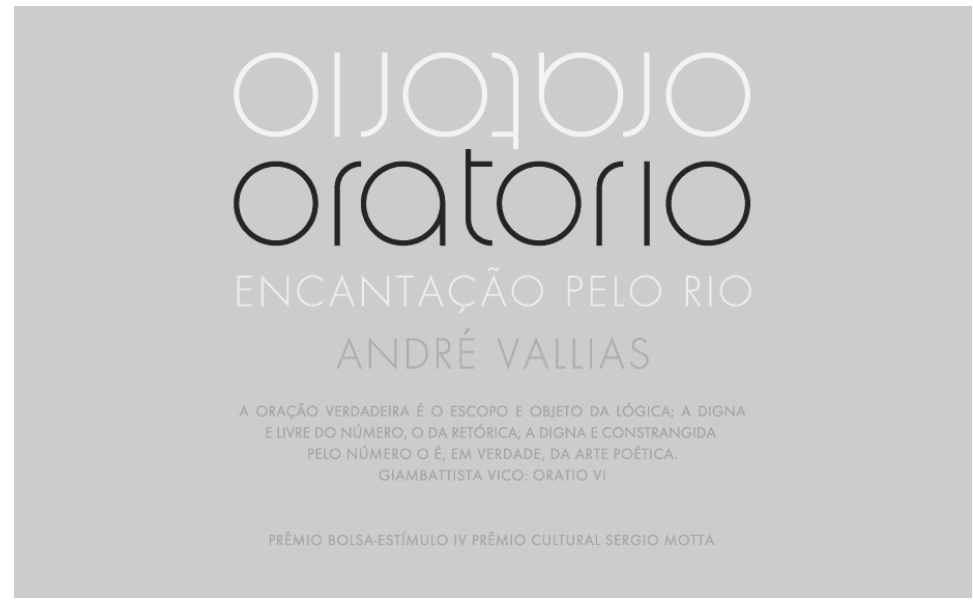

Figura 1 - Captura de tela de página de Oratório $^{14}$

Ultrapassando a tela inicial, o título da obra se avulta e aquele recurso da sobreposição das letras, usado na tela anterior, complexifica-se: a palavra oratório surge reiterada em quatro linhas que estabelecem, entre si, uma relação espectral; além disso, outra diferença importante faz-se notar: o fato de que, nesta tela, ao leitor não cabe nenhum tipo de interação e a ele não se dá nenhuma opção, a não ser seguir em frente, enfrentar um pouco mais o poema que, a partir dessa tela o acolhe com um som grave, soturno e repetitivo. Algumas expectativas são quebradas desde esse momento do poema: aquela relacionada ao meio material escolhido pelo poeta para a inscrição de sua obra - a apresentação de uma poesia como "digital" tem criado expectativas em torno da interatividade que comumente se indica como uma característica definidora do meio; aquela relacionada com a escolha vocabular do título. Oratório, em seu sentido mais difundido, é o cômodo da casa (ou mesmo um nicho, armário ou móvel em que se guardam e expõem os objetos e imagens religiosas) dedicado à prática devocional, no entanto, em um sentido menos popular, designa "local funesto ou sombrio em que, como punição, se encarceravam alguns presidiários", de onde derivou a expressão "estar de oratório", que significa "preparar-se para sofrer algum desgosto iminente" (Houaiss, 2001, p. 2075).

\footnotetext{
${ }^{14}$ Disponível em: <http://www.andrevallias.com/oratorio/>.
} 
Há, portanto, um inicial confronto com o leitor que, diante de uma poesia digital muito pouco pode fazer, a não ser clicar e aguardar o surgimento de uma nova tela, embalado por uma sonoridade lúgubre que faz com que ele se questione a respeito de um primeiro sentido talvez eufórico do título do poema Oratório: encantação pelo Rio. Se o vocábulo oratório esconde nas suas acepções semânticas a devoção e o desespero, o vocábulo "encantação" também traz estranhamento. Sinônimo de "encantamento", cujo uso é muito mais popular, "encantação" parece fazer ressoar - talvez pelo estranhamento derivado de um uso pouco comum - outras palavras dentro de si: encanto, canto, ação.

Há que se considerar se o leitor, diante desta tela inicial, da qual ele não tem como recuar - a não ser abandonando a obra - não se encontra, metaforicamente, em "estado de oratório", dado o desconforto do não controle - o que, ironicamente, contradiz a corrente caracterização das obras digitais e sua propalada possibilidade de abertura e interação - e a insegurança a respeito do que vai encontrar. A leitura das páginas seguintes pode esclarecer a hipótese.

É levando consigo o desconforto que o leitor acede à próxima página do poema (figura 2).

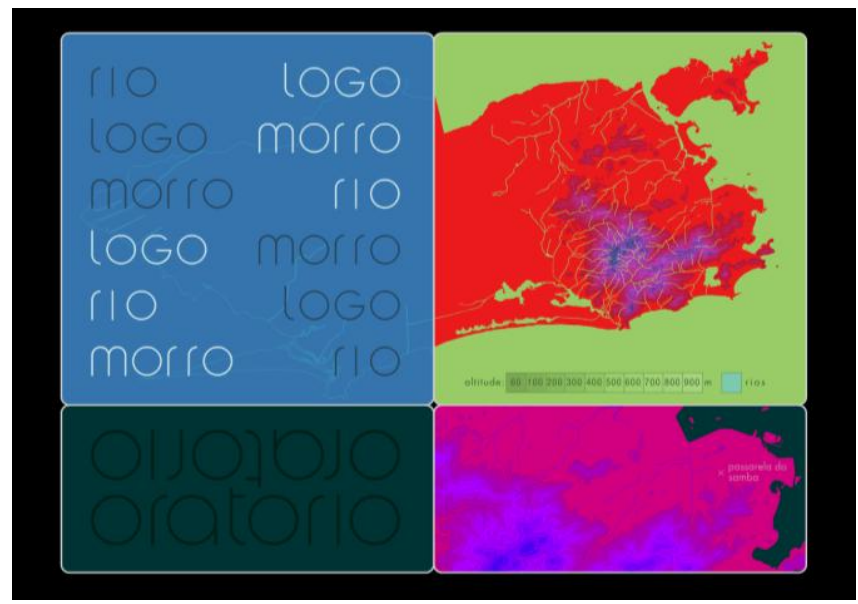

Figura 1 - Captura de tela de detalhe de página de Oratório $^{15}$

${ }^{15}$ Disponível em: 〈http://www.andrevallias.com/oratorio/load.html〉. 
O tom lúgubre do som da página anterior se mantém, mas agora podemos dizer que há uma música, não mais apenas um som, um rumor. Isso porque o leitor é capaz de reconhecer, ao fundo dessa camada sonora tão lúgubre, o ritmo compassado do samba. Como se um estrato de significado se adicionasse aos significados da página anterior, o compasso sonoro ritmado e prontamente reconhecido pelo leitor é distorcido por essa tonalidade lúgubre e disfórica que parece não se adequar aos primeiros significados que os vocábulos "oratório" e "encantação" revelam. O som indefinível na primeira página (figura 1) e o samba distorcido, na segunda, por conseguinte, reiteram o expediente de rasura dos significados mais comuns dessas palavras, abrindo espaço para outros significados que lentamente emergem.

Esses outros significados, disfóricos, dão-se a revelar de forma menos opaca nessa segunda página (figura 2), que expõe ao leitor uma tela dividida em quatro campos. À esquerda, acima do título (em composição espelhada, mais uma vez), um jogo móbil com as palavras "rio", "logo", "morro" dá acesso, por um procedimento hipertextual, a um poema a sua direita, que substitui a imagem cartográfica do Rio de Janeiro (figura 3).

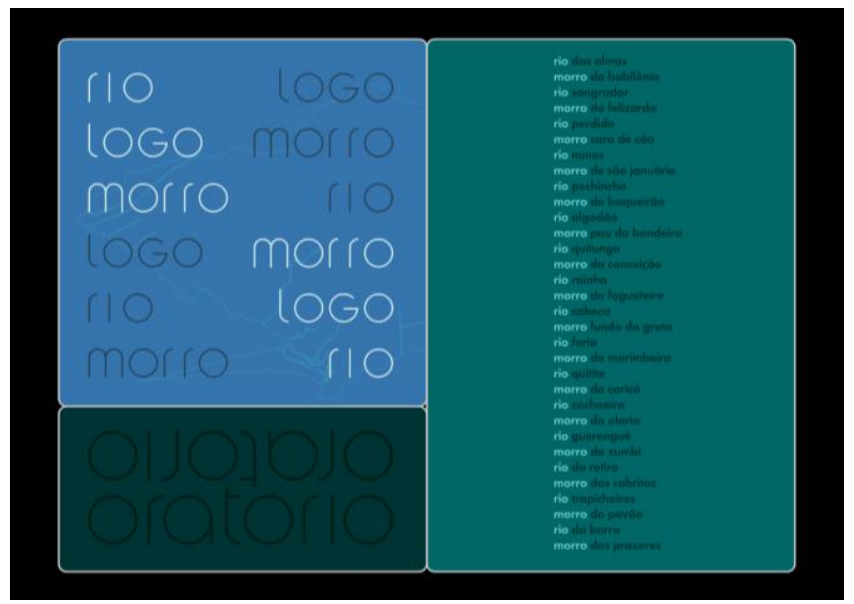

Figura 2 - Captura de tela de página de Oratório $^{16}$

\footnotetext{
${ }^{16}$ Disponível em: <http://www.andrevallias.com/oratorio/load.html〉.
} 
A aparente enumeração simples e alternada de nomes de morros e rios do Rio de Janeiro é organizada em 32 versos metrificados com certa regularidade: três sílabas métricas para os versos ímpares e seis sílabas métricas para os pares - mesmo quando a regularidade não se mantém, a alternância entre versos mais longos e mais curtos permanece. Ao clicar sobre o poema, surge uma sua continuação. Isso acontece por mais três vezes, o que faz com que o poema totalize 128 versos. A metrificação alternada e a repetição das palavras "rio" e "morro", associadas ao samba lugubremente distorcido produz um efeito quase hipnótico e leva ao deslizamento semântico entre as palavras "rio" e "morro" - substantivos - e as mesmas palavras "rio" e "morro" verbos. A essa altura, mais uma camada de significado se sobrepõe e a ambiguidade que perscrutava o leitor na alternância dos sentidos eufóricos e disfóricos em "oratório" e na distorção do ritmo do samba, o atinge mais uma vez, na convivência entre os verbos (na verdade, substantivos que se transmudaram em verbos) "rir" e "morrer".

Voltando à tela anterior (figura 2), vê-se que o quadro abaixo, à direita, dá acesso a outra página, com a representação topográfica da cidade do Rio Janeiro, em que estão assinaladas três localidades: "Passarela do samba", "Corcovado", "Favela da Rocinha".

Cada um dos desses locais assinalados no mapa é um hiperlink que dá acesso a outra página (figura 4) que, por sua vez, divide-se em dois quadros contendo, à esquerda, um poema (cuja totalidade só se apreende ao se clicar sobre uma seta que indica a sua continuação) e, à direita, uma representação gráfica ${ }^{17}$ de seu arranjo tônico. A composição sonora da página ainda é um samba distorcido, no entanto, percebe-se que sons foram acrescentados e que remetem a uma espécie de murmúrio que o acompanha.

\footnotetext{
${ }^{17}$ Poderíamos chamar tal representação de (topo)gráfica, uma vez que ela remete não apenas às especificidades das sílabas tônicas dos versos, mas também à peculiar geografia do Rio de Janeiro, tomada por morros e já glosada no primeiro poema que analisamos. A estrutura de tal representação é utilizada por André Vallias em outras obras (Nous n'avons pas compri Descartes, de 1990 e TRAKLTAKT, de 2003, por exemplo) e consiste na manipulação do software autoCAD; evidentemente, em cada uma dessas obras a ferramenta possibilita a composição de efeitos e significados diferentes.
} 


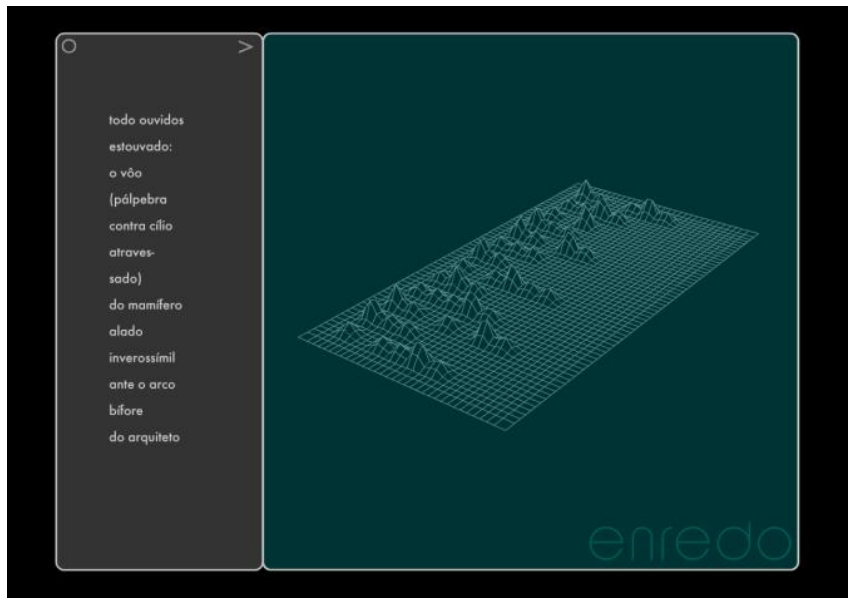

Figura 3 - Captura de tela de página de Oratório $^{18}$

Se o Rio de Janeiro se fazia presente desde o subtítulo do poema, se a sua peculiaridade topográfica (profusão de morros e rios) serviu de matéria à primeira composição verbal mais alentada do poema, aqui o leitor é convidado a abandonar uma perspectiva antes externa - como aquela que os famosos passeios de helicóptero pela orla proporcionam e, efetivamente, entrar nesse espaço, nesses três espaços escolhidos pelo poeta para expressar a sua peculiar encantação pela cidade.

O poema cujo acesso se dá por meio do hiperlink "Passarela do samba" constitui-se de uma bela e melancólica visada a respeito de um desfile de carnaval, em uma perspectiva "rasteira",19 de quem está na própria passarela diante da magnitude da festa - não apenas do evento em si, mas de seu "antes" e "depois", das expectativas que gera e das ressonâncias que o seu fim produz. O título "Enredo" tem explícitas ligações com o universo do carnaval, mas é importante sublinhar que o vocábulo também abriga os significados "mentira", "ardil", "ludíbrio" (Houaiss, 2001, p. 1156); mais uma vez, a estratégia é de revelar, sob uma camada de significados

\footnotetext{
${ }^{18}$ Disponível em: <http://www.andrevallias.com/oratorio/load.html〉.

${ }^{19}$ A expressão é tomada de Willi Bolle (2004, p. 76) que, contrapondo a perspectiva de Guimarães Rosa à de Euclides da Cunha a respeito do sertão, afirma que "O olhar de Guimarães Rosa sobre o sertão é o exato oposto das vistas euclidianas do alto: é uma perspectiva rasteira. Enquanto o ensaísta-engenheiro sobrevoa o sertão como num aeroplano, o romancista caminha por ele como por uma estrada-texto." No caso do poema digital de André Vallias que estamos analisando, ambas as perspectivas parecem se suceder ao longo do percurso que percorremos, na sucessão de páginas que o constituem.
} 
eufóricos, significados disfóricos, tornando ambígua a representação da cidade e o testemunho de "encantação" do poeta.

Para acessar o próximo poema, o leitor precisa retornar à página que abriga o mapa da cidade do Rio de Janeiro e clicar no hiperlink "Corcovado". Ali, é recebido, ainda, por um samba distorcido, em que o som da cuíca proporciona o embalo rítmico e também lúgubre. A disposição da página é a mesma da página anterior, mas a cor de fundo em que o gráfico em autoCAD é construído é, agora, verde. O título do poema, "Locução", - e, por que não dizer, a cor do fundo - antecipa o que será o seu assunto: uma partida de futebol, mas também a violência que espreita, contida, na arquibancada, e irrompe brutal depois da partida, nas ruas. Aceder ao poema por meio da rubrica em hiperlink "Corcovado" permite algumas leituras. Sabe-se que do Maracanã é possível avistar a estátua do Cristo Redentor, e vice-versa. Informação de que o poeta parece fazer uso, uma vez que inicia o poema com uma descrição que funde duas imagens: a de um goleiro à espera do chute decisivo e a da estátua do Cristo Redentor, no topo do morro. Essa fusão de imagens cria uma intricada "confusão" de perspectivas: afinal, no poema, a perspectiva é do goleiro que olha para a estátua? É da estátua que vê o goleiro? É do espectador que, da arquibancada, vê goleiro e vê estátua em poses idênticas?

[estático: de

mãos espalmadas

mais vazias que o des

terrado

olhar de um

suicida] (...)

Além disso, outras metáforas cristãs vão se arrolando ao longo do poema, compondo um quadro dantesco, infernal, em que a alegria dá lugar à violência e em que a estátua do Redentor perde os seus significados simbólicos, a despeito da sua "omnipresença" e se reduz a sua terrena materialidade:

\author{
o simulacro \\ oco e alvo \\ que a urbe \\ estatui: christus \\ redemptor \\ homini (...)
}


Na última página, à qual o leitor tem acesso por meio do hiperlink "Favela da rocinha", encontra-se a mesma disposição de imagens e texto que, agora, está sobre fundo vermelho. O que se ouve é de uma sonoridade compassada, mas que dificilmente poderia ser aproximada ao ritmo do samba. "Escritura" é a palavra escolhida para ladear o poema desta página.

O poema constrói um percurso por um morro - que o hiperlink na página anterior anunciou como sendo o Morro da Rocinha -, subjetivando a cartografia, evidenciando o jogo de forças (violento) entre a ocupação humana e a geografia inóspita:

\author{
sela \\ indômito \\ e dilacera \\ o dorso \\ inerme \\ da montanha
}

O poema parte dessa primeira relação de forças e a aprofunda a partir de diversas elaborações metafóricas, nunca, no entanto, explorando diretamente o clichê da violência relacionada à favela - a palavra "favela" não aparece no poema, apenas no hiperlink da página anterior. Assim, a violência está no dilaceramento da paisagem pela ocupação humana, pela abertura de trilhas e estradas e pela construção de casas (como se nota no excerto acima) e também em:
sela
cravejada
de tijolos
e concreto
armado
até
os dentes:
cidadela
teia

As metáforas constroem uma paisagem geográfica que dá suporte a uma paisagem poética (ou seria o contrário?) que estabelece um vínculo inextricável entre o espaço geográfico e as práticas humanas que neles se dão, como se a gênese da violência pudesse ser encontrada nessa realidade mineral e, ao mesmo tempo, como se a violência o tivesse 
contaminado para sempre. Ressoa, na leitura do poema - sublinhe-se que "leitura", nesse caso, está relacionada com a matéria verbal em relação íntima com a sonoridade e a imagem que o compõem - as reflexões de Michel de Certeau a respeito do espaço:

Existe espaço sempre que se tomam em conta vetores de direção, quantidades de velocidade e a variável tempo. O espaço é um cruzamento de móveis. É de certo modo animado pelo conjunto dos movimentos que aí se desdobram. Espaço é o efeito produzido pelas operações que o orientam, circunstanciam, o temporalizam e o levam a funcionar em unidade polivalente de programas conflituais ou de proximidades contratuais. [...] Em suma, o espaço é um lugar praticado (1998, p. 202).

Isso porque convivem, no poema, dois tempos em um único lugar: trata-se do Rio de Janeiro dos anos 1930, quando as estradas da Rocinha eram palco das corridas automobilísticas do circuito da Gávea: ${ }^{20}$

outrora

o trajeto

supérfluo

das flechas

de prata [...]

e de um Rio de Janeiro atual:
agora:
aorta única
do labririnto
[...]
fluindo
sem guarda
e sem grito
nas curvas
inflexas
do ex-
trampolim
do diabo

\footnotetext{
${ }^{20}$ A esse respeito consulte-se a belíssima coleção de fotografias disponibilizadas no Flickr pela ONG Rocinha. Disponível em: <https://goo.gl/i3Nk5S>. Acesso em: mar. 2015.
} 
Nesse sentido, e para retomar De Certeau (2008), a geografia explicitada pelo poema só faz sentido porque é atravessada pelo tempo e porque ganha significado a partir do que, ao longo desse tempo e nesse espaço foi praticado. Embora o poema explicite dois tempos com o uso de marcadores temporais bastante objetivos - "outrora" e "agora" - é possível perceber que há uma imbricação de um tempo em outro, como se atestando a impossibilidade de isolá-los, como se atestando o fato inescapável de que só podemos conhecer um atravessando o outro.

O Rio de Janeiro de agora traz a memória do Rio de Janeiro de outrora; o Rio de outrora só nos é dado a conhecer a partir do que conhecemos do Rio de agora - curioso notar que a sonoridade homóloga de outrora e agora não só aproxima as duas palavras, como também faz parecer que uma contém a outra, levando para o nível da materialidade linguística essa peculiar relação entre temporalidades diversas.

O que perdura pelos tempos está literalmente enraizado no espaço é o que expõe os últimos versos do poema:

a árvore
$[\ldots .$.
borda a copa
com folhas
que entoam
no alto
histórias
inscritas
a fogo
no tronco

Finalizado o percurso pela totalidade do poema - objeto compósito de matéria verbal, sonora e gráfica -, o leitor cumpre o percurso inverso e, fechando sucessivas páginas, depara-se novamente com o título do poema (figura 1), o qual se pode ler mais uma vez em sua específica composição na página.

Vale a pena, nesse sentido, repensá-lo. A sua disposição espectral, na qual a palavra "oratório" aparece duas vezes, como se em uma delas funcionasse como o reflexo da outra remete (ou antecipa?) aos significados ambíguos que, no decorrer do poema, se foram atando ao Rio de Janeiro. Desde as sonoridades escolhidas, que parecem, em um primeiro momento, dissonantes em relação ao Rio de Janeiro dos guias 
turísticos e das novelas de Manuel Carlos, passando pelos poemas que também assinalam percepções ambíguas e plurais a respeito de diferentes tempos e espaços da cidade, o que se compõe é mais do que simplesmente uma imagem invertida do Rio, expondo sua complexa realidade geográfica-social e cultural - algo que tem sido feito nas últimas décadas por romances como Cidade de Deus, só para citar aquele que de certa forma deu maior visibilidade a esse esforço. Oratório faz isso também, mas não só, uma vez que não abandona a outra imagem, aquela idílica, do samba, da alegria, da paisagem deslumbrante, do passado dourado.

Oratório, a palavra, tem, no título, a seus pés, sua imagem narcísica e, ao expô-la, o poeta parece querer expor a própria cidade em seu fascínio por si mesma - tal como Narciso - ao mesmo tempo que denuncia, por meio dessa mesma imagem, o que está nela corrompido. "Encantação" que ultrapassa a contemplação narcísica e motiva/canta a ação.

\section{À guisa de conclusão}

Katherine Hayles (2001), como já mencionamos, compara a literatura produzida em contexto digital como um "monstro esperançoso", compósito nem sempre bem resolvido de linguagens e códigos diversos, produto típico de uma era cultural que tem a possibilidade de reunir - e reelaborar, remixar - tais linguagens e códigos em um único metameio, o computador ligado em rede. Além de linguagens e códigos convergem, nesse metameio, heranças e expectativas.

No caso da literatura, heranças de uma cultura que a viu consolidarse enquanto tal - a cultura impressa - e as expectativas nem sempre otimistas em relação ao seu futuro em uma era em que "os saberes e o imaginário contemporâneos não se organizam [...] em torno do eixo letrado, nem o livro é o único foco ordenado do conhecimento" (Canclini, 2008, p. 33).

A metáfora do monstruoso já fora utilizada no contexto literário por Alain Robbe-Grillet (1969, p. 14) em texto que reflete sobre o seu fazer romanesco e sobre a recepção problemática dos seus romances na metade do século XX:

Toda a organização literária existente (desde o editor até o mais modesto leitor, passando pelo livreiro e pelo crítico) não pode fazer 
outra coisa além de lutar contra a forma desconhecida que tenta se impor. Os espíritos mais favoráveis à ideia de uma transformação necessária, aqueles mais dispostos a reconhecer o valor de uma pesquisa, apesar de tudo continuam a ser os herdeiros de uma tradição [...]. O balbuciante recém-nascido será sempre considerado como um monstro, mesmo por aqueles apaixonados pela experiência.

As considerações de Hayles (2001) não carregam a gravidade, e porque não dizer a amargura, da formulação de Robbe-Grillet (1969). Além do fato de que o romancista francês está refletindo acerca da incompreensão de que sua própria obra foi vítima, por parte de todo o sistema literário consolidado, a diferença também reside, talvez, em uma percepção de monstruosidade que indica a ausência de forma em Robbe-Grillet (1969), ao passo que, em Haylles (2001), indica a multiplicidade de formas.

Para além de uma sutileza semântica, a ligeira diferença de significados no mesmo vocábulo, "monstro", utilizado por ambos os autores para designar um objeto literário que é de difícil apreensão e compreensão pela "organização literária existente", evidencia uma alteração de perspectiva interessante que, ousaria afirmar, está relacionada também com especificidades da cultura digital: a convergência midiática possibilita a reunião, em um único dispositivo, de linguagens e códigos diferentes; a tela do computador ligado em rede, diferentemente da página do livro, faz da leitura uma decodificação simultânea de diferentes textualidades; o autor cada vez mais tem condições de manejar outros códigos que não apenas o verbal para compor a sua obra.

Nesse contexto, o próprio conceito de obra literária, tal como se consolidou e tal como a descreveu Reinaldo Laddaga (2002), citado em outro momento, como um objeto íntegro que ultrapassa as práticas cotidianas, parece estar distante da realidade atual - e muito próximo, ainda, da realidade de Robbe-Grillet (1969), talvez por isso a sua percepção (na verdade a percepção dos críticos da época, que ele amarguradamente constata) tão pejorativa do monstruoso como o que é informe.

A obra Oratório, de André Vallias, compósito equilibrado de matéria verbal e outras matérias ditas espúrias, secundárias para o que convencionalmente designamos como literatura, só pode ser apreendida em sua especificidade de texto literário digital se a sua "nova forma" não 
for confundida com uma "ausência de forma" literária e se a presença das ditas matérias espúrias for efetivamente encarada como parte da obra em si, não como ruído incidental que deve ser contornado para a adequada decodificação do texto. Para tanto, o crítico literário tem a sua disposição uma metalinguagem fundada no contexto da cultura impressa, mas cujos limites devem ser questionados com ousadia e encarados com o mesmo voluntarismo do de Robbe-Grillet (1969).

\section{Referências}

BOLLE, Willi (2004). Grandesertão.br. São Paulo: Duas Cidades; Editora 34.

BOLTER, David Jay; GRUSIN, Richard (2000). Remediation: understanding new media. Cambridge: MIT Press.

CANCLINI, Néstor García (2008). Leitores, espectadores, internautas. São Paulo: Iluminuras.

CHARTIER, Roger (2012). O que é um autor? Revisão de uma genealogia. Tradução de Luzmara Curcino Ferreira. São Carlos: EDUFSCar.

COSTA, Cristina (2002). Fiç̧ão, comunicação e mídias. São Paulo: SENAC.

DE CERTEAU, Michel (1998). A invenção do cotidiano: artes de fazer. 3. ed. Tradução de Ephraim Ferreira Alves. Petrópolis: Vozes.

FOLLAIN, Vera (2010). Narrativas em trânsito. Contracampo, Rio de Janeiro, n. 21, p. 26-39.

HAYLES, Katherine N. (2009). Literatura eletrônica: novos horizontes para o literário. São Paulo: Global; Fundação Universidade Federal de Passo Fundo.

HOUAISS, Antônio (2001). Dicionário Houaiss da Lingua Portuguesa. Rio de Janeiro: Objetiva.

KUCINSKAS, Jean; MOSER, Walter (2007). A estética à prova de reciclagem cultural. Revista Scripta. Belo Horizonte, v. 11, n. 20, p. 17-42.

LADDAGA, Reinaldo. Uma fronteira do texto público: literatura e meios eletrônicos. In: OLINTO, Heidrum Krieger; SCHOLLHAMMER, Karl Erik (2002). Literatura e mídia. Rio de Janeiro: Puc-Rio; São Paulo: Loyola, p. 17-31.

LÉVY, Pierre (2008). Cibercultura. 2. ed. Tradução de Carlos Irineu da Costa. São Paulo: Ed. 34. 
LENTRICHIA, Frank; MCLAUGHLIN, Thomas (1995). Value and evaluation. In: LENTRICHIA, Frank; MCLAUGHLIN, Thomas. Critical terms for literary study. 2. ed. Chicago and London: The University Chicago Press. p. 177-185.

NUNBERG, Geofrey (1993). The places of books in the age of electronic reproduction. Representations, Oakland, n. 42, p. 13-37. Special Issue: Future Libraries.

PORTELA, Manuel; GRÁCIO, Rita (2012). Poesia em rede: poesia portuguesa em blogues e sítios. Texto digital, Florianópolis, v. 8, n. 2, p. 302-336.

REIS, Pedro (2012). Media digitais: novos terrenos para a expansão da textualidade. Texto digital, Florianópolis, v. 8, n. 2, p. 256-272.

ROBBE-GRILLET, Alain (1969). Um caminho para o romance do futuro. In: ROBBE-GRILlET, Alain. Por um novo romance. Tradução de T. C. Netto. São Paulo: Documento. p. 13-28.

SANTOS, Alckmar Luiz dos (2003). Leitura de nós: ciberespaço e literatura. São Paulo: Itaú Cultural.

SANTOS, Alckmar Luiz dos; SALES, Cristiano de (2011). Notícia da atual literatura brasileira digital. Revista Outra Travessia, Florianópolis, $2^{\circ}$ sem. Dossiê Especial, v. I: Literaturas Digitais.

SOUZA, Roberto Acízelo de (2010). Literatura. In: CEIA, Carlos (Coord). Edicionários de termos literários. Disponível em: <http://www.edtl.com.pt/>. Acesso em: 20 set. 2015. Disponível em: < http://goo.gl/0sgDrc>. Acesso em: 20 set. 2015.

VALLIAS, André (2003a). Oratório: encantação pelo Rio. Disponível em: <http:/ / www.andrevallias.com/oratorio/\#>. Acesso em: 20 set. 2015.

VALLIAS, André (2003b). Trakltakt. Disponível em: <http:/ / www.andrevallias.com/trakltakt/>. Acesso em: 20 set. 2015.

VALLIAS, André (1990). Nou n'avons pas compris Descartes. Disponível em: <http://www.andrevallias.com/poemas/nous.htm>. Acesso em: 20 set. 2015.

WIESE, Maíra Borges (2012). A poesia digital de André Vallias. Dissertação (Mestrado em Estudos Literários e Culturais) - Universidade de Coimbra, Coimbra.

ZUMTHOR, Paul (1987). La letra y la voz. Tradução de Julián Presa. Madri: Cátedra.

Recebido em dezembro de 2014.

Aprovado em maio de 2015. 
Rejane C. Rocha

\section{resumo/abstract/resumen}

\section{"Monstro esperançoso": a respeito de Oratório, de André Vallias}

Rejane C. Rocha

A apreensão das obras literárias produzidas em contexto digital e que fazem uso das potencialidades das novas mídias deve levar em consideração que o conceito de literatura e os parâmetros utilizados para valorar os objetos literários são provenientes da era da cultura impressa. Embora não se trate de decretar o fim dessa era, é inegável que o contexto digital tem engendrado novas formas de produzir, ler e fazer circular o texto literário, o que acarreta, também, outros critérios de valoração, apreensão e definição da literatura. Atento a essas questões, este texto procura ler o poema digital Oratório, de André Vallias, delineando as suas especificidades enquanto texto literário produzido (e lido) no contexto digital.

Palavras-chave: literatura, contexto digital, André Vallias, Oratório.

\section{"Monstro esperançoso": Some thoughts on Oratório, by André Valias}

Rejane C. Rocha

The apprehension of literary works produced on digital context and which make use of the new media's potential should take into consideration that the concept of literature and the parameters used to value literary objects are descendent from the print culture's era. Although it's not about to decree the end of that era, it's undeniable that the digital context has engendered new ways to produce, read and circulate the literary text, which also carries other valuation's criteria, apprehension and definition of literature. Aware of these issues, this text seeks to read the digital poem Oratório, by André Valias, outlining its specificities as a literary text produced (and read) in the digital environment.

Keywords: literature, digital context, André Vallias, Oratório.

\section{"Monstruo esperanzado": respecto de Oratório, de André Vallias}

Rejane C. Rocha

La aprehensión de las obras literarias producidas en ámbito digital y que tratan de las posibilidades de las nuevas midias debe considerar que el concepto de literatura y los parámetros utilizados para valorar los objetos literarios son advenidos de la era de la cultura impresa. Aunque no se trate de dictar el fin de esa era, es innegable que el ámbito digital ha engendrado nuevas maneras de producir, leer y repercutir el texto literario, lo que exige también otros criterios 
de valoración, aprehensión y definición de literatura. Atento a esas cuestiones, este texto busca leer el poema digital Oratório, de André Vallias, delineando sus especificidades como texto literario producido (y leído) en el ámbito digital.

Palabras clave: literatura, ámbito digital, André Vallias, Oratório. 